\title{
KULTURA AUTOBIOGRAFICZNA
}

ANETA DUDA*

Katolicki Uniwersytet Lubelski

\section{Dyskurs blogów modowych - między kooperacją a kooptacją}

\section{Streszczenie}

Blogi są często przedmiotem entuzjastycznych opinii, wskazujących, że przyczyniają się do decentralizacji, demokratyzacji komunikacji i rozwoju kultury uczestnictwa. W artykule starano się ustalić, czy analizowane tu blogi modowe rzeczywiście odzwierciedlają zmiany w użytkowania mediów, tj. służą odzyskiwaniu pola dla oddolnych inicjatyw i sprzyjają pożądanej w sferze publicznej różnorodności informacji i opinii. Potencjał dialogowy blogów, opierając się na Bachtinowskich definicjach i kryteriach „dialogowości”, badano w odniesieniu do mody, łącząc krytyczną analizę dyskursu z analizą zawartości. Wskazano też czynniki monologizowania dyskursu, a także zrekonstruowano proces instytucjonalizowania ról ich autorek, odchodzenie od dyskursu autentyczności i modelu relacyjnego. Wykazano, że analizowane blogi modowe, świadomie komercjalizowane, z każdym rokiem coraz bardziej stawały się monologowymi, jednokierunkowymi i autopromocyjnymi kanałami transmisji zasad obowiązujących w przemyśle mody.

Stowa kluczowe

krytyczna analiza dyskursu, blogi modowe, dialog, monolog

* Kontakt z autorką: aduda@kul.lublin.pl; ORCID 0000-0003-2349-3517. 
Już ponad dekadę temu zwrócono uwagę na potencjał treści generowanych przez użytkowników Internetu (ang. user-generated content) i procesy oddolnego rozpowszechniania informacji. Wiele osób uważało, że radykalnie zrekonfigurują one relacje między twórcami i odbiorcami. Ci drudzy mieli oceniać, krytykować oraz włączać się w krążenie treści ${ }^{1}$. Pisano o powrocie do czasów spontanicznej komunikacji, swoistej rearchaizacji, wtórnej oralności i rodzącej się inteligencji kolektywnej². Partycypacyjny charakter nowych mediów, umożliwiający każdemu użytkownikowi publikowanie własnych opinii, dał asumpt do porównania komunikacyjnej rewolucji Web 2.0 do wynalezienia druku przez Gutenberga ${ }^{3}$. W tych przemianach dostrzegano możliwość przekazania władzy medialnej obywatelom. Nastawienie na konwersację i współpracę, a nie na korzyści finansowe, miało odróżniać nowe kanały dystrybuowania informacji od mediów głównonurtowych ${ }^{4}$.

Blogi uznano za tę część wirtualnego świata, który najlepiej zrealizuje te oczekiwania. Eksponowano decentralizację w ich modelu komunikacyjnym, niski poziom regulacji i kontroli nad przepływem informacji, sporą interakcyjność, elastyczność w formie, doborze treści i ich wykorzystywaniu ${ }^{5}$. Miały zakończyć erę jednostronnych przekazów, być miejscem ekspresji osobowości, pasji i sposobu postrzegania rzeczywistości przez ich autorów ${ }^{6}$. Blog modowy był opisywany jako „studium przypadku demokracji medialnej” , „forma społecznego dokumentu” zachęcająca do dialogu wzmacniającego moda uliczna ${ }^{8}$ oraz jako „demokratyczny obszar, w którym opinia publiczna, a nie modelki, celebryci czy projektanci, staje

1 Henry Jenkins, Sam Ford, Joshua Green, Spreadable Media, Creating Value and Meaning in a Networked Culture (New York: University Press, 2013).

2 Kazimierz Krzysztofek, „WEBski świat: mądrość tłumów sieciowych czy zbiorowe nieuctwo? Wprowadzenie”, w: Andrew Keen, Kult amatora. Jak Internet niszczy kulturę, tłum. Małgorzata Bernatowicz, Katarzyna Topolska-Ghariani (Warszawa: Wydawnictwa Akademickie i Profesjonalne, 2007), 13.

3 Hugh Hewitt, Blog. Understanding the Information Reformation That's Changing Your World (Nashville: T. Nelson Publishers, 2005), 47-48.

4 Shayne Bowman, Chris Willis, We Media. How audiences are shaping the future of news and information (The Media Center at The American Press Institute, 2003), 12, dostęp 21.04.2019, http://www.hypergene.net/ wemedia/download/we_media.pdf.

5 Maciej Mrozowski, Media masowe. Władza, rozrywka i biznes (Warszawa: Oficyna Wydawnicza ASPRA-JR, 2012).

6 Bonnie A. Nardi, Diane J. Schiano, Michelle Gumbrecht, Luke Swartz, „«I’m Blogging This» A Closer Look at Why People Blog”, Communication of the ACM (2004), dostęp 18.04.2019, https://www.academia. edu/32459914/Im_blogging_this_A_closer_look_at_why_people_blog.

7 Susie Khamis, Alex Mun, „The Three Cs of Fashion Media Today: Convergence, Creativity \& Control”, Journal of Media Arts Culture 7 (2010): 3.

8 Jess Berry, „Street-Style. Fashion Photography, Weblogs and the Urban Image”, w: Fashion Capital. Style Economies, Sites and Cultures, red. Jess Berry (Oxford: Interdisciplinary, 2012), 129. 
się liderami - kreatorami mody" ". Widziano w nim także kontrkulturową, anty-hegemoniczną praktykę, alternatywną wobec głównego nurtu mody, a nawet zdolną do przeciwstawienia się mu, i prowadzącą do powstania oddolnego ruchu, czy wręcz „ekstremalnie demokratyczną formę dziennikarstwa" ${ }^{10}$.

Tym euforycznym opiniom na temat rozwoju kultury uczestnictwa, rosnącej władzy obywateli, kreatywności odbiorców i słabnącego znaczenia selekcyjnej roli mediów głównego nurtu z czasem zaczęły towarzyszyć jednak głosy podważające wartość sieciowej współpracy czy jakość treści generowanych przez użytkowników. Coraz częściej można się spotkać z dość jednostronną krytyką, która zdaniem Kazimierza Krzysztofka w Web 2.0 widzi „nie mądrość tłumu, a «rój dyletantów», kolektywną ignorancję i kradzież własności intelektualnej, motłoch sieciowy karykaturujący demokrację, przeradzający ją w paido- i ochlokrację - rządy dzieciaków i motłochu, po których prawem Arystotelesowskiego cyklu może przyjść tylko nowa tyrania" ${ }^{11}$. Co więcej, sięganie po zaawansowane narzędzia - wyposażone w sztuczną inteligencję - niektórzy postrzegają jako proces algorytmizacji ludzkiego zachowania czy wręcz „odmóżdżania”. A wtedy trudno mówić o kolektywnej mądrości - właściwszym określenie jest zbiorowa ignorancja ${ }^{12}$.

Kolejną kwestią dyskutowaną w literaturze przedmiotu jest status konsumenta w nowoczesnej mediasferze. Marketingowcy wskazują, że media społecznościowe umożliwiają klientom swobodne wyrażanie opinii o produktach i usługach. Dowodzą zatem, że wzmacniają one rolę konsumentów, którzy do tej pory mieli niewielkie możliwości kontaktu z dużymi przedsiębiorstwami. I rzeczywiście, taka publiczna dyskusja o produktach może być znacząca, zwłaszcza wtedy, gdy dotyczy wpływu firmy na środowisko przyrodnicze, zdrowie, kulturę i gdy może zmienić na ich politykę. Niewątpliwie konsumenci mają dziś dużo większe możliwości wyrażania opinii, można jednak zadać pytanie, czy z nich korzystają.

Naukowcy krytykują media internetowe także za korzystanie z nieopłaconej pracy ich użytkowników ${ }^{13}$ oraz stosowanie neoliberalnych reguł zatrudniania, którym muszą się podporządkować dostawcy treści. Już dekadę temu Gina Neff i Andrew Ross wskazywali, że skomputeryzowana i usieciowiona infrastruktura wpływa na doświadczenia zawodowe

\footnotetext{
9 Tamże, 129.
}

10 Jay Rosen, The Weblog. An Extremely Democratic Form in Journalism, dostęp 11.04.2018, http://extremedemocracy.com/chapters/Rosen_weblog.pdf.

11 Krzysztofek, „WEBski świat”, 16.

12 Kazimierz Krzysztofek, „Zmiana permanentna? Refleksje o zmianie społecznej w epoce technologii cyfrowych”. Studia Socjologiczne 4 (2012): 31.

13 Christian Fuchs, Digital Labour and Karl Marx (London-New York: Routledge, 2014). 
pracowników kreatywnych ${ }^{14}$. Dzisiaj wciąż aktualne są takie problemy, jak: brak gwarancji zatrudnienia, zamazywanie granicy między pracą i czasem wolnym, traktowanie siebie jak markowego produktu rynkowego ${ }^{15}$ oraz konieczność nieustającego podwyższania kwalifikacji dla zwiększania efektywności zawodowej. Trafnie podsumował to Thomas Friedman, reporter „New York Timesa”: „Moje pokolenie miało łatwo. Musieliśmy jedynie «znaleźć» pracę. Nasze dzieci natomiast (...) będą musiały ją «wymyślić», wciąż się uczyć i wciąż prowadzać innowacje” ${ }^{16}$. Nieustanna kreatywność, kolejne aspiracje i innowacyjność okazują się najważniejszymi wartościami pozwalającymi zaistnieć we współczesnej mediasferze. Blogowanie modowe jest częścią tak scharakteryzowanych kultury cyfrowej i współczesnego środowiska pracy w mediach.

\section{METODOLOGIA BADAŃ WŁASNYCH}

\section{Metoda i pytania badawcze}

Zastosowana metodologia opiera się na krytycznej analizie dyskursu (KAD) wspomaganej analizą zawartości, która umożliwi ilościowy pomiar wybranych czynników. KAD koncentruje się na relacjach między tekstem a ideologicznym wymiarem kontekstu społecznego, wskazuje na uwikłanie władzy i nierówności społecznych w dyskurs ${ }^{17}$, na to, w jaki sposób władza jest konstytuowana przez zyskiwanie w nim dominującej. Zakłada, że ukazywanie tych powiązań zwiększa refleksywność społeczną i może prowadzić do tworzenia nowych, twórczych i sprawiedliwszych niż wcześniejsze rozwiązań instytucjonalnych ${ }^{18}$.

Sięgam po KAD, by ustalić, czy analizowane blogi rzeczywiście odzwierciedlają zmianę w użytkowaniu mediów, tj. odzyskiwanie pola dla drobnych, oddolnych inicjatyw, a pośrednio również osłabianie pozycji centralnych mediów i wielkiego przemysłu. Interesuje mnie, czy i ewentualnie w jakich obszarach komunikacyjnych - odbiorcy mają możliwość współtworzenia treści tych blogów. Czy naukowy dyskurs o kreatywnych, niezależnych, amatorskich blogach modowych nie odwraca uwagi od ich autopromocyjnego i komercyjnego charakteru,

\footnotetext{
14 Gina Neff, Venture Labor. Work and the Burden of Risk in Innovation Industries (Cambridge: MIT Press, 2012); Andrew Ross, Nice Work if You Can Get it (New York: NYU Press, 2009).

15 Alice E. Marwick, Status Update. Celebrity, publicity, and branding in the social media age (New Haven, CT: Yale University Press, 2013).

16 Thomas L. Friedman, „Need a Job? Invent It”, The New York Times, 30.03.2013, dostęp 12.04.2019, https:// www.nytimes.com/2013/03/31/opinion/sunday/friedman-need-a-job-invent-it.html.

17 Anna Duszak, Norman Fairclough, Krytyczna analiza dyskursu. Interdyscyplinarne podejście do komunikacji społecznej (Kraków: Universitas, 2008), 17.

18 Tamże, 17.
} 
od zhierarchizowanego systemu mody, w którym są one osadzone i który je sponsoruje? Czy komercyjna współpraca nie wpływa na ich wiarygodność? Czy blogi sprzyjają pożądanej różnorodności informacji i opinii w sferze publicznej? A może relacje między blogerem a czytelnikami są mniej symetryczne i dwukierunkowe, niż można by zakładać, co kwestionowałoby demokratyczny, oddolny potencjał takiego kanału? Czy blogerki są podmiotami demokratyzującego się przemysłu modowego, narzędziami redystrybucji władzy symbolicznej, czy raczej nowym przekaźnikiem przemysłu mody, skuteczniejszym niż wcześniej używane, bo odbieranym jako bardziej wiarygodny (ze względu na popularność)? Czy w epoce neoliberalnego kapitalizmu kognitywnego ${ }^{19}$ istnieje jakaś możliwa do opisania różnica między tymi dwoma funkcjami?

Można by posłużyć się w tym przypadku określeniem „semiotyczne pole bitwy” Johna Fiske’a, i wskazać, że to na właśnie na nim ma rozgrywać się walka między siłami inkorporacji a siłami sprzeciwu ${ }^{20}$. Nie będę jednak procesów użytkowania i komercjalizowania nowych mediów opisywała w kategoriach walki. Traktuję mody blogowe bardziej jako dążenie do kompromisu, tytułowej kooperacji między strategiami narzucanymi przez przemysł mody a praktykami blogerek, które chciałyby kreować własne, przyjazne dla czytelników i atrakcyjne medium, korzystając jednocześnie z korporacyjnego wsparcia. Często nawet nie zdają sobie sprawy, że w pewnym momencie przekraczają punkt krytyczny między jednym a drugim.

\section{Charakterystyka materiału badawczego}

W marcu 2019 roku przeprowadziłam analizę dwóch polskich blogów z branży modowej dobranych według kryteriów popularności i czasu prowadzenia: Maffashion.pl [MF] (liczba fanów: ponad 862 tys.) oraz Macademiangirl.com [MG] (ponad 290 tys.). Następne w kolejności były blogi Jessiki Mercedes Kirschner - Jemerced.com (ok. 258 tys.), Katarzyny Tusk - Makelifeeasier.pl (ok. 140 tys.) i Weroniki Załazińskiej - Raspberryandred.net (ok. 116 tys.). Blogi modowe są najchętniej czytanymi stronami w blogosferze $\mathrm{e}^{21}$ (ok. 15 proc. udziału ${ }^{22}$ ), zajmują

19 Zob. szerzej: Yann Moulier Boutang, Cognitive Capitalism (Cambridge: Polity Press, 2011).

20 Pod. za: John Storey, Studia kulturowe i badania kultury popularnej. Teorie i metody, tłum. Janusz Barański (Kraków: Wydawnictwo Uniwersytetu Jagiellońskiego, 2003), 32.

21 Anna Kubik, Najlepsze blogi modowe, Influencer.pl, 28.06.2016, dostęp 18.02.2019, http://www.influencer. $\mathrm{pl} / 237 /$ najlepsze-blogi-modowe-zobacz-ich-wlascicielki.

22 Ranking i badanie polskiej blogosfery 2016, Mediarun, 26.10.2016, dostęp 20.02.2019, http://mediarun.com/ pl/digital/internet/blogerzy-wiedza-jak-zachecic-czytelnikow.html. 
też pierwszą pozycję w rankingu zainteresowania dziennikarzy pozostałych mediów ${ }^{23}$, a tym samym również marketingowców szukających kanałów do promocji marek.

Autorką MG jest trzydziestoletnia Tamara Gonzalez Perea, która prowadzi również autorską rubrykę w magazynie „Glamour”. Jest zapraszana do programów rozrywkowych, takich jak Dzień Dobry TVN, i wielu innych audycji telewizyjnych i radiowych. W 2018 roku została jedną z prowadzących program Pytanie na śniadanie w TVP 2. Jej blog powstał w 2011 roku, a rok później w plebiscycie magazynu „Press” uznano go za najlepszy w sektorze mody. Druga z blogerek, trzydziestojednoletnia Julia Kuczyńska, w 2011 roku zdobyła nagrodę dla autora najlepszego bloga przyznaną przez organizatorów „Warsaw Fashion Street”, a rok później została „Człowiekiem Roku Polskiego Internetu”. W 2013 roku magazyn „Brief” uznał ją za najbardziej wpływową blogerkę w Polsce, a w 2017 - na świecie. Międzynarodowa agencja marketingowa Tribe Dynamics oszacowała medialną wartość marki Kuczyńskiej na niemal sześćdziesiąt pięć milionów dolarów ${ }^{24}$.

Analizie poddałam materiał z czterech losowo wybranych miesięcy każdego roku od 2009 (MF) / 2011 (MG) do 2018 roku. Łącznie przeanalizowałam 1250 postów (586 na blogu MF i664 na blogu MG) oraz 6210 komentarzy i odpowiedzi blogerek. W pracy korzystam też z wyników wcześniejszych badań zrealizowanych w 2017 roku $^{25}$ - uaktualniam je, a także uzupełniam wywód o analizę zmian dyskursu, a przede wszystkim sięgam po inne kategorie badawcze.

„Post” definiuję jako elektroniczną wypowiedź (potencjalnie rozpoczynającą dyskusję), natomiast „komentarze” jako odpowiedzi na posty. Na blogu MG nowe treści pojawiają się dość systematycznie, średnio trzy-cztery razy w tygodniu; niektóre z nich są w języku angielskim. Na blogu MF z kolei liczba postów wyraźnie spadła, kiedy założycielka rozpoczęła oficjalną współpracę z środowiskiem modowym i reklamowym (również jako modelka).

\footnotetext{
${ }^{23}$ Najpopularniejsze polskie blogi, Newsbook, 17.06.2016, dostęp 18.02.2019, https://newsbook.pl/2016/06/17/ najpopularniejsze-polskie-blogi.

24 Elizabeth Doupnik, Julia Kuczyńska Tops List of 20 Most Revenue-Generating Social Personalities, „WWD”, 23.01.2017, dostęp 18.02.2019, http://wwd.com/business-news/media/20-most-influential-bloggers-10759942 .

25 Aneta Duda, Medialne socjotechniki brandcastingu. Hybrydyzacja. Uwiarygodnianie. Zadaniowość (Lublin: Katolicki Uniwersytet Lubelski, 2018).
} 
TABELA 1. LICZBA POSTÓW NA BLOGACH

\begin{tabular}{|c|c|c|c|c|c|c|c|c|c|c|c|c|}
\hline \multirow[b]{2}{*}{$\begin{array}{c}\text { Nazwa } \\
\text { bloga }\end{array}$} & \multicolumn{12}{|c|}{ Rok } \\
\hline & ஜे & 웅 & $\vec{\Xi}$ & స్తి & $\stackrel{m}{\stackrel{N}{\circ}}$ & 离 & $\stackrel{n}{\stackrel{2}{\circ}}$ & $\begin{array}{l}0 \\
\stackrel{-}{\circ} \\
\end{array}$ & 공 & $\stackrel{\infty}{\circ}$ & 茔 & $\begin{array}{c}\text { Śr. liczba } \\
\text { postów na } \\
\text { miesiąc }\end{array}$ \\
\hline MG & - & - & 144 & 283 & 235 & 299 & 222 & 237 & 229 & 231 & 1880 & 20 \\
\hline MF & 134 & 224 & 249 & 185 & 101 & 97 & 85 & 175 & 163 & 168 & 1581 & 13 \\
\hline
\end{tabular}

Źródło: opracowanie własne.

\section{Struktury dyskursywne i kategorie analityczne dialogu}

Badam potencjał dialogowy blogów, opierając się na Bachtinowskich definicjach i kryteriach dialogowości ${ }^{26}$, którą definiuję jako pożądaną postawę otwarcia na innych, rozumienia ich, dialektyczną więź podmiotów, zakładającą ich odrębność i zarazem równorzędność. Nastawienie na dialog oznacza ciągłe dopuszczanie słuchającego do współtworzenia wypowiedzi, zaufanie do cudzego słowa i przeżywanie tego słowa, ale i pobieranie nauk, poszukiwanie czy nawet wymuszanie sensu wypowiedzi ${ }^{27}$. Inaczej jest w przypadku monologu, który Bachtin określa jako mowę nieskierowaną do odbiorcy i nieprzewidującą odpowiedzi, ograniczającą wieloznaczność intencji, tłumiącą wielogłosowość słowa i taką, w której nie ma miejsca na spotkanie z innym. Dominującej kulturze monologowej badacz przeciwstawia „ambiwalencję karnawałową”, będącą dyskursywnym odpowiednikiem średniowiecznego karnawału, zawieszającego zasady i relacje władzy obowiązujące poza tym okresem. Język karnawałowych form i symboli przesiąknięty jest poczuciem względności prawd i władzy, logiką odwrotności i nieustannych przemieszczeń „góry” i „dołu”, a także najrozmaitszymi typami parodii i trawestacji ${ }^{28}$.

Osadzając swoje rozważania w takiej ramie teoretycznej, będę mogła się przyjrzeć napięciom między dwoma przeciwstawnymi dyskursami: dialogowym i monologowym. Sięgam po tę opozycję, znając argumenty wskazujące na przemienność wzajemnych relacji elementów dialogu i monologu, polifonii i homofonii w kulturze. Kwestii tych nie rozważam tutaj, odsyłam jedynie do opracowania Pawła Bohuszewicza ${ }^{29}$. Dla celów analitycznych rozdzielam

\footnotetext{
${ }^{26}$ Michaił Bachtin, „Problem tekstu: próba analizy filozoficznej”, tłum. Jerzy Faryno, Pamiętnik Literacki 68 (1977), 3: 280-282.

27 Tamże, 282.

28 Michaił Bachtin, Twórczość Franciszka Rabelais'go a kultura ludowa średniowiecza i renesansu, tłum. Anna i Andrzej Goreniowie (Kraków: Wydawnictwo Literackie, 1975), 68.

29 Paweł Bohuszewicz, „Dialog i monolog: o względności genologicznych przeciwstawień”, Litteraria Copernicana 15 (2015), 1: 28-39.
} 
jednak te pojęcia, aby pokazać, w jaki sposób analizowane blogi umożliwiają tworzenie dyskursu bądź ograniczają taką możliwość, stymulują albo wyciszają różnorodność opinii, wzmacniają albo osłabiają internetowy potencjał dialogowości i partycypacji. Mówiąc językiem Bachtina, chodzi o to, w jakich obszarach otwierają pole niezależnym, polifonicznym, „karnawalizującym głosom”, a na ile tłumią wielogłosowość słowa.

W analizie blogów Bachtinowskie elementy dialogu będę pojmowała następująco:

- konwersacyjność - dopuszczanie, zachęcanie odbiorcy do wypowiedzi, współzależność/ wzajemne oddziaływanie nadawcy i odbiorcy; sprzężenia zwrotne, które są wyznacznikiem interakcyjności i dynamiki procesów komunikacyjnych,

- polifonia - wielogłosowość, czyli zderzanie różnych, w tym konfrontacyjnych głosów, punktów widzenia, co może wskazywać na autentyzm zachowań językowych; różnorodność toposów,

- karnawalizacja - zachowania niekonformistyczne, nietypowe, ekscentryczne, np. wulgaryzmy; konwersacja bez wyraźnie określonych ról nadawcy i odbiorcy, otwarta, swobodna, nieunikająca tematów tabu.

W procesie analitycznym korzystam natomiast z kategorii przedstawionych przez Teuna van Dijka, takich jak kontekst oraz semantyczna i formalna struktura dyskursu ${ }^{30}$. Kontekst uważa się za „środowisko” objaśniające dyskurs. W tym opracowaniu skoncentruję się na specyfice analizowanego medium, a zwłaszcza tych jego cechach, które czynią go tak atrakcyjnym kanałem dla działań marketingowych.

W warstwie formalnej należy zwrócić uwagę zarówno na ogólną strukturę tekstu (mogącą zawierać np. część aktywującą, taką jak pytania, sugestie lub prośby), jak i graficzne środki pozajęzykowe (krój, kolor czcionki, podkreślenia, rysunki czy fotografie). Formalna struktura dyskursu to także wszelkie figury retoryczne, służące np. personalizacji i familiaryzacji medialnego dyskursu. Jeśli chodzi o analizę warstwy semantycznej, van Dijk akcentuje poszukiwanie zarówno znaczenia pojedynczych elementów tekstu, tj. wybór określonych słów czy wydobycie ich ukrytego sensu, jak i znaczenia ogólnego. Istotne są zwłaszcza wykorzystane toposy, ponieważ umożliwiają nadawcy kontrolowanie dyskursu, prowadzą do formułowania logicznych i intencjonalnych konkluzji, wyrażają istotę grupy i określają specyfikę dyskursu.

Ukazanie współwystępowania nacisków komercyjnych (kontekstu) i narracji blogerek umożliwi mi wskazanie zmian, jakim podlegają strategie dyskursywne, i argumentów, po które sięgają w nowych kontekstach. Dynamikę konstrukcji tekstowych będę zatem wskazywać na przykładzie różnych elementów.

30 Teun A. van Dijk, „Dyskurs jako struktura i proces”, w: Dyskurs jako struktura i proces, red. Teun A. van Dijk, tłum. Grzegorz Grochowski (Warszawa: Wydawnictwo Naukowe PWN, 2001), 12. 


\section{WYNIKI BADAŃ WŁASNYCH}

\section{Kontekst}

Nie ma tu miejsca, by podejmować rozważania o szeroko pojętym „środowisku” objaśniającym dyskurs mediów internetowych, o ich komercjalizacji, czy - jeszcze szerzej - o kapitalizmie i jego osiągnięciach, ale i negatywnych konsekwencjach stosowania logiki wolnorynkowej. Dość powiedzieć, że w pewnych okresach z różnych powodów niektóre elementy zyskują pozycję dominującą w kulturze, by w innym czasie ustąpić miejsca kolejnym ważnym sensom i wytworom. Niekiedy najważniejsza jest religia, innym razem sztuka, a kiedy indziej nauka lub - co wydaje się charakteryzować współczesność - interes ekonomiczny i generowanie zysku. Norman Fairclough dodaje, że to właśnie wolnorynkowa logika prowadzi do kumulacji w mediach internetowych „symbiotycznych procesów ekonomicznej kalkulacji, manipulacji i tworzenia designu" ${ }^{31}$. Digitalizacja ułatwia komercjalizację mediów, czyni ten rodzaj komunikacji policzalnym i poddającym się monitorowaniu, dzięki czemu łatwo ją ekonomicznie optymalizować i efektywnie utowarowiać.

Prywatne blogi są efektywnym narzędziem marketingu, dlatego że rekomendacje blogerów okazują się dobrze widoczne. Marketingowcy podkreślają, że ciągle aktualizowane treści blogów z odpowiednio pozycjonowanymi postami, zoptymalizowanymi pod względem SEO (ang. search engine optimisation), to jest bogatymi we frazy kluczowe, mogą zapewnić marce wysokie miejsce w wyszukiwarkach. Poza tym blogi dają szansę na tworzenie silnych relacji między autorem a czytelnikami i reklamy mogą być dzięki temu wplatane w nieustający i sprawiający wrażenie prywatnego dialog, postrzegany jako coś zupełnie odmiennego od drażniących prób wywarcia wpływu na przykład przez treści marketingowe w telewizji. Z tego powodu zajmują wysoką pozycję wśród źródeł informacji promocyjnych pod względem zaufania do publikowanych tam komunikatów, popularności i wpływu na odbiorców.

Około 11 procent wydatków, jakie przedsiębiorstwa przeznaczają na marketing w mediach społecznościowych, przeznaczanych jest na promocję na blogach i budowanie relacji z influencerami ${ }^{32}$. Wprawdzie ta ostatnia pozycja nie jest notowana najwyżej w marketingowych budżetach, niemniej około 65 procent marek pozyskuje influencerów ${ }^{33}$. Z drugiej zaś strony warto zaznaczyć, że aż 61,7 procent blogerów czeka na e-maile z propozycjami współpracy

\footnotetext{
31 Norman Fairclough, „Language in New Capitalism”, Discourse \& Society 13 (2002): 164.

32 Technorati Media, Digital Influence Report (2013), 4-13, dostęp 13.04.2019, http://technorati.com/wp-content/uploads/2013/06/tm2013DIR1.pdf.

33 Tamże.
} 
od agencji reklamowych czy bezpośrednio od przedsiębiorstw ${ }^{34}$. Relacje między blogerami a firmami zapewniającymi im wsparcie finansowe nie są przejrzyste. Przypomina to problem z niezależnością mediów, od których firmy kupują (lub decydują się przestać kupować) powierzchnię reklamową.

Innym sposobem komercjalizowania treści medialnych trafiających do sfery publicznej jest zarządzanie własnym wizerunkiem (marka osobista, personal/self branding itp.), czyli strategiczna, zindywidualizowana autoprezentacja zgodna z logiką rynkową i podkreślająca atrakcyjność oferty. Dotyczy to nie tylko osób publicznych, ale też internautów, między innymi, blogerek. Egocasting, którego częścią jest komodyfikacja cielesności ${ }^{35}$, staje się normatywnym sposobem postępowania na konkurencyjnym rynku. Alice Marwick wskazuje, że self branding to „podstawowa strategia środowiska 2.0”36 i jest „nierozerwalnie związany z technologią mediów społecznościowych, które umożliwiają autopromocję na szeroką skalę" ${ }^{37}$. Akty medialnej autokreacji, w połączeniu z podkreślaną przedsiębiorczością, stają się podstawą biograficznej narracji blogerów.

W rozważaniach o kontekście trzeba wspomnieć też o medium, jednym z podstawowych loci tworzenia dyskursu publicznego. Analizowany tu rodzaj strony internetowej ma wyjątkową cechę: umożliwia wszystkim uczestnikom wzięcie udziału w dyskursie. W każdej chwili można odczytać posty, komentarze, sprawdzić linki. Technologicznie zaimplementowaną możliwość komentowania treści postów uznaję za najważniejszą cechę blogów powiązaną z badanymi tu konwersacyjnością i polifonią zwiększającą potencjał internetowej dialogowości.

\section{Formy blogów}

Oba analizowane blogi są zdominowane przez zdjęcia. Początkowo stanowiły one wizualne wsparcie tekstu, ilustrowały obecny w poście materiał słowny i odnosiły się najczęściej do jednej stylizacji modowej. Obecnie są najważniejszym elementem stron, a większość z nich, zwłaszcza na blogu MF, przedstawia modelki i celebrytów, a nie same blogerki. Zdjęcia Kuczyńskej pojawiają się coraz rzadziej, a jeśli już, to w reklamach, w których bierze udział. Posty zawierają niekiedy jedynie tytuły i zdjęcia. Jeśli tekst się pojawia, jest dłuższy niż wcześniejsze i dotyczy polecanych produktów (pojawia się wyeksponowane logo oraz obrazowe

\footnotetext{
34 Poznaj polskich blogerów, BLOGmedia (2016), dostęp 14.04.2019, http://www.blog-media.pl/raport.

35 Teresa Joanna Sikora, „Komodyfikacja cielesności w erze późno nowoczesnej”, w: Ciało $w$ dobie współczesności. Wybrane zagadnienia z problematyki obrazu własnego ciała, red. A. Brytek-Matera (Warszawa: Difin, 2010), 239-260.

36 Alice E. Marwick, Status Update. Celebrity, Publicity, and Branding in the Social Media Age (New Haven: Yale University Press, 2013), 164.

37 Marwick, Status Update, 166.
} 
i tekstowe hiperłącza do e-sklepów), bądź stylizacji wykorzystujących markowe ubrania. W przypadku MF posty nie zawsze są pisane przez autorkę, pod niektórymi widnieje pseudonim CosmQueen. Tamara Perea z kolei prowadzi na blogu również własny sklep internetowy.

Początkowo na blogach modowych można było znaleźć quasi-samodzielnie wykonane zdjęcia z domów blogerek bądź bliskiego otoczenia, przez co nieco odkrywały prywatność, prawie nigdy niewidoczną dla czytelnika magazynów mody. Wraz z rosnącą popularnością blogów i jednocześnie ich profesjonalizacją zmienia się jednak estetyka zdjęć. Amatorskie ujęcia i „okołodomowe” tło zostają zastępowane profesjonalnymi sesjami zdjęciowymi, wykorzystującymi odpowiednie techniki stylizacji, ustawienia fotograficzne i precyzyjne aranżacje, za które odpowiada sztab specjalistów.

Generyczna struktura dyskursu, zawierająca próby angażowania odbiorców: zadawanie im pytań, odpowiadanie na komentarze i tym podobne, niweluje autorytatywność wypowiedzi, zmniejsza dystans między nadawcą a odbiorcą i dowodzi, że odbiorca jest dla nadawcy ważny. W pierwszych latach duża liczba komentarzy mogła być wyzwaniem dla blogerek. Tematy modowe, raczej niekontrowersyjne, „bezpieczne” (zwłaszcza w ujęciu Kuczyńskiej i Perei), przyciągały uwagę. Pod każdym postem pojawiało się kilka bądź kilkanaście komentarzy wyrażających uznanie i podziw dla blogerek. To zdecydowanie dominujący element wypowiedziach czytelniczek. Tamara Perea wciąż dziękuje im za komentarze: „hehe dziewczyny jestescie niemozliwe! dziekuje za tak liczne pozytywne epitety pod moim adresem!!! aaaaaaaaaaaaaaaaa DZIEKUJE!”, a Julia Kuczyńska odpowiadała na takie wypowiedzi tylko w pierwszych czterech latach funkcjonowania bloga.

Pytania zamieszczane w postach nie prowokują dyskusji, a często wskazują konkretny wybór: „Nie masz jeszcze nic w tym kolorze? Nic straconego! Sklepy on-line oraz sieciówki mają w swojej ofercie mnóstwo ubrań i dodatków”. Takie „bezpieczne” tematy, szczególnie w połączeniu z zamkniętymi pytaniami, nie zachęcają do krytycznych czy jakikolwiek innych niestandardowych wypowiedzi, a przez to powodują monologizowanie dyskursu. Nawet pozytywny odbiór postów, o czym wspomina się w dużej liczbie komentarzy, nie wpływa na podejmowanie przez czytelników dialogu. Większość wypowiedzi ogranicza się do maksymalnie pięciu słów i są równie powierzchowne jak treści postów. Dyskutowanie, polemizowanie czy krytykowanie prowadzące do polifonii się nie pojawia. Nie spotkałam się z jakimkolwiek „karnawałowym zawirowaniem” w formie negatywnych komentarzy czy odmiennych opinii. Jedyne wypowiedzi, które identyfikowałam jako przejaw karnawalizacji, to te, w których obecne były ekspresyjne określenia hiperboliczne, silnie ocenne (jedynie pozytywne) wyrazy, wielkie litery, wykrzykniki. Takie emocjonalne zaangażowanie pojawia się głównie przy ocenie wyglądu blogerek: „La Pearl: Julietttt aaaaaaaaaaaaa!!!! oczy są boskie”; „Iva: Great great great look !!”. 
Konwersacyjność, początkowo widoczna w komunikacji blogerek, ustępuje miejsca bardziej sformalizowanym formom pisania. Odpowiedzi na komentarze stają się coraz krótsze, są realizacją ujednoliconej formuły (przeproszenie za dłuższą nieobecność, podziękowanie i wyrażenie sympatii) albo w ogóle się nie pojawiają. Praktyka „kopiuj-wklej” podważa zasadność blogowej interakcji, zwłaszcza kiedy niemal wszystkie wypowiedzi blogerek są identyczne, niezależnie od komentarza, i wydaje się, że ich zadaniem jest zakończenie dyskusji.

Dominujący obecnie styl glamour, widoczny na zdjęciach z prestiżowych pokazów mody, zostaje niekiedy skontrastowany poradnikowymi tekstami o promocjach w supermarketach, typu „Co kupić na promocjach w popularnych drogeriach?”. Zachodzący proces komercjalizacji i standaryzacji dyskursu spotyka się z konkretną reakcją: na blogu MG pojawia się coraz mniej komentarzy, a na blogu MF od pięciu lat nie ma ich już w ogóle.

WYKRES 1. LICZBA KOMENTARZY NA BLOGACH MF I MG W LATACH 2009/2011-2018

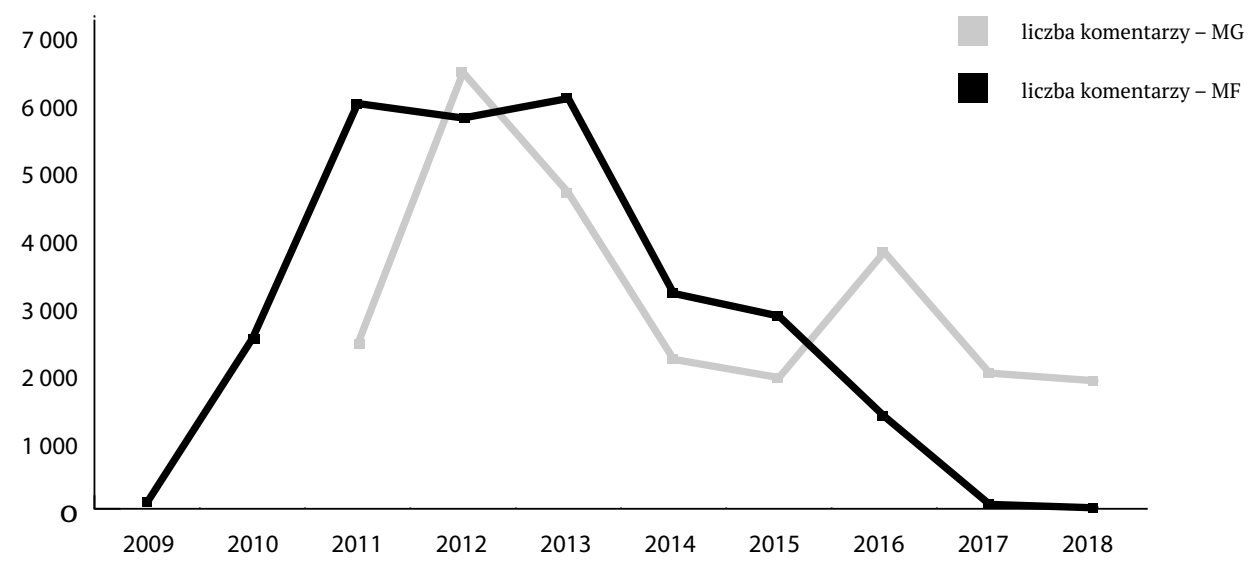

Źródło: Opracowanie własne.

Strategie dyskursywne

Początkowo obie blogerki sięgały po dyskursywne praktyki podkreślające ich podobieństwo do czytelników. Usiłowały zmniejszać dystans i chciały być postrzegane jak koleżanki, zwykłe dziewczyny o typowych zainteresowaniach i z typowymi problemami. Blog MF był rodzajem dziennika, w którym Kuczyńska opowiadała o swoim codziennym życiu, jednocześnie dzieląc się wskazówkami na temat ubioru. Posty były pisane prostym językiem, pojawiały się w nich liczne emotikony, co przyciągało uwagę, ale też sprzyjało tworzeniu swobodnej, koleżeńskiej 
atmosfery: „W weekend zamierzalam grzecznie pojechac na uczelnie ale rozlozyla mnie choroba. Chyba po zobaczeniu nowego planu zajec stracilam zdrowie heh".

Ów swobodny ton, wzmacnianie emocjonalnego związku między blogerkami a czytelnikami, obniżanie czy też zasłanianie różnicy w statusach traktuję jako przejaw karnawalizacji. Podobnie jak techniki autodeprecjacji, po które sięgały blogerki, śmiejąc się ze swoich potknięć, podkreślając własne ograniczenia i błędy i zwykłość życia. Jak jednak twierdzą Edward McQuarrie, Jessica Miller i Barbara Phillips: „Język samodeprecjacji, który pojawia się w postach blogerów, może dotyczyć cech fizycznych, złych nawyków lub kłopotliwych momentów, ale deprecjacja nigdy nie odnosi się do mody. Blogerzy nigdy nie kpią z własnego stylu. (...) Blogerka może powiedzieć, że potknęła się na wysokich obcasach, ale nigdy nie powie, że ma problem z wyborem marki czy koloru butów"38. Rzeczywiście, nie zdarzyło się, by któraś z blogerek prosiła fanki o radę bądź nawet przyznawała, że nie umie podjąć decyzji. Były jedynie opisy niezręczności, na których pojawienie się nie zawsze można mieć wpływ: „Dzisiejszy zestaw, powstawał przyznaję nieco na wariata, bo miałam tylko chwilę, żeby się przebrać ... (stąd jestem taka wygnieciona, za co przepraszam) ... Oczywiście zaczęło lać. Możecie obserwować co się dzieje z moimi włosami kiedy jest wilgotno”. Takie elementy występowały tylko w początkowej fazie prowadzenia blogów.

WYKRES 2. DYSKURS „ZWYKŁEJ” DZIEWCZYNY

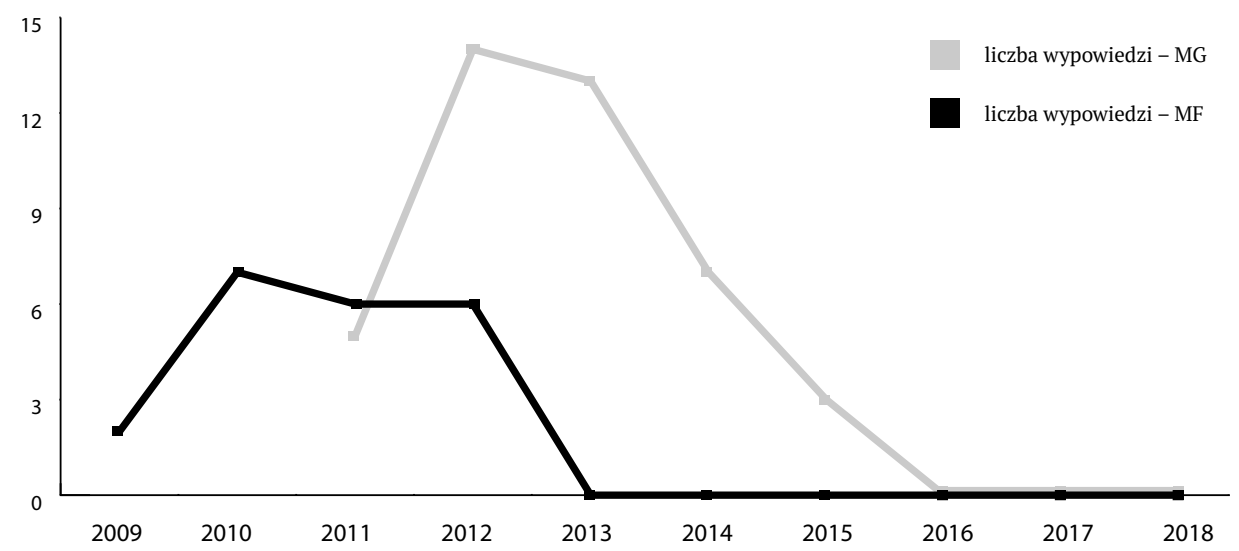

Źródło: Opracowanie własne.

38 Edward McQuarrie, Jessica Miller, Barbara Phillips, „The Megaphone Effect. Taste and Audience in Fashion”, Blogging Journal of Consumer Research 40 (2013), 1: 152. 
Z czasem dyskurs familiarny przechodzi w coraz bardziej oficjalną „życzliwość”, mniej spontaniczną pseudoprywatność, by w końcu przekształcić się w „dojrzały” biznesowy styl, wskazujący na zinstytucjonalizowaną kooptację do branży modowej. Na blogu MG wciąż pojawiają się materiały mające wskazywać na autentyczność blogerki, na przykład kiedy pojawia się bez makijażu i poddaje (pozytywnej) ocenie kolegi wizażysty. Promowane kosmetyki próbuje włączyć w narrację autentyczności, spontaniczności, ale już nie zwykłej dziewczyny.

Blogerki coraz rzadziej prezentują własne modowe wybory, a w zamian zaczynają przekazywać wiedzę i przyjmują rolę ekspertek. Sporadycznie dzielą się emocjami, np. w relacjach z wydarzeń modowych, w których biorą udział. Na blogu MF ostatnie posty opisujące tego typu doświadczenia pojawiły się w kwietniu 2013 roku.

Zwiększający się dystans do czytelników: coraz mniejsza liczba komentarzy, a te, które się pojawiają, są autorstwa innych blogerów modowych, krótsze odpowiedzi lub ich brak, rekomendowanie coraz droższych, luksusowych marek, promocyjny charakter postów, relacje z udziału blogerek w popularnych programach wskazują na proces instytucjonalizowania się blogerek i przemiany w celebrytki. Rola instytucjonalna jest przeciwieństwem form karnawalizujących dyskurs. Powierzchowna konwersacja przebiega już głównie według modelu góra-dół.

\section{Struktury semantyczne}

Polifoniczność dyskursu wiąże się z różnorodnością wykorzystywanych toposów i poruszanych tematów. Początkowo toposy dotyczyły własnych stylizacji modowych. W pierwszym poście Tamara Perea przedstawiła samodzielnie wykonany projekt butów. Blogerki podkreślały wtedy swoją inwencję w odnajdywaniu niedrogich, a dobrych jakościowo kosmetyków „zwyklaków” - i ubrań z second-handów, a także deklarowały chęć dzielenia się pomysłami modowymi i stylizacjami własnego pomysłu. Budowały swoją wiarygodność na niezależności wyborów i spójności swojego stylu. Perea podkreślała: „Mój ubiór z pewnością wyraża to jaka jestem, dlatego jednego możecie być pewni: będzie kolorowo!”.

Początkowo dla blogerek istotne było coś w rodzaju Lévi-Strauss'owskiego bricolage'u ${ }^{39}$. Bricoleur - jak pisze Claude Lévi-Strauss - to ten, kto używa własnych rąk i posługuje się środkami zastępczymi w porównaniu z działaniami zawodowców, a także zwraca uwagę na elementy „gotowe”, bo chce przystosować je do własnych celów. Manipulując nimi i umieszczając w innym układzie, bricoleur nadaje im niejako nowy sens. Sięga po istniejące rzeczy, to, co jest dostępne, doskonałe lub niedoskonałe, tanie lub drogie, proste lub skomplikowane,

39 Claude Lévi-Strauss, Myśl nieoswojona, tłum. Andrzej Zajączkowski (Warszawa: Wydawnictwo Naukowe PWN, 1969), 30. 
„pytając” o możliwość nadania nowych znaczeń ${ }^{40}$. Blogerki zatem samodzielnie tworzyły stylizacje modowe i testowały łączenie różnych elementów ubioru już posiadanych z właśnie kupionymi. Podejmowały też próby odtwarzania aktualnych trendów, choć drogie markowe ubrania pojawiały się w ich stylizacjach (zwłaszcza Kuczyńskiej) raczej na prawach wyjątku. Poza tym posty pisane przez Kuczyńską często służyły katalogowaniu jej codziennego ubioru (przykładowy tytuł postu: Co dziś założyłam), niekoniecznie zaś do prezentacji ubrań specjalnie przygotowanych do sesji zdjęciowej.

Obecne toposy bazują na relacjach fotograficznych ze światowych pokazów mody, na najnowszych kolekcjach znanych projektantów i ich kampaniach reklamowych, również tych, w których Kuczyńska bierze udział. Przedstawiają modnie ubranych celebrytów, modelki zawsze młode, atrakcyjne i mające na sobie wyłącznie drogą odzież.

Treści zamieszczane na obydwu blogach są do siebie podobne. Pojawiające się (nie zawsze) teksty brzmią, jakby były skopiowane z PR-owskich materiałów: „Produkty są bardzo praktyczne, a ich mocno napigmentowane formuły gwarantują długotrwałość i nieskazitelny efekt. Te profesjonalne kosmetyki są dedykowane każdej kobiecie, która stawia na perfekcyjny makijaż!”. Nie zawierają uwag krytycznych na temat modowej rzeczywistości, są „łatwe i przyjemne” w odbiorze, po prostu atrakcyjnie przetwarzają albo jedynie redystrybuują promocyjne zasoby rynkowe.

Na blogu Tamary Perei znajduje więcej treści poradnikowych, dotyczących pielęgnacji urody, diety, sposobów spędzania czasu wolnego, relacji damsko-męskich niż u jej konkurentki. Jednak toposy także wyraźnie wskazują na proces instytucjonalizowania się w roli celebrytki (relacjonowanie udziału w Pytaniu na śniadanie czy Tańcu z gwiazdami i zachęta, by na nią głosować), bądź ekspertki, kiedy doradza: „Jak osiągnąć sukces zaczynając od zera?”. Kuczyńska z kolei, jeśli pojawia się na swoim blogu, to w materiałach podsumowujących jej reklamową aktywność („2018 w pigułce - MAFFASHION”). Jej posty bywają pisane w liczbie mnogiej, jakby była wyrazicielką aktualnych trendów modowych - pośrednikiem między czytelnikiem a przemysłem mody: „Na fashion weekach w Nowym Jorku, Mediolanie czy Paryżu ulice zostały opanowane przez monochromatyczne stylizacje we wszystkich odcieniach beżu. Beż, obok kobaltu i fuksji to jeden z naszych ulubionych kolorów tej wiosny”.

Formą legitymizacji blogów przestają być relacje z odbiorcami, których komentarze mogły stanowić źródło satysfakcji i w ogóle umożliwiały blogerkom kontynuowanie aktywności. Teraz tę rolę przejmują branżowi znajomi, komentujący stylizacje w nadziei na zwiększenie zainteresowania swoimi blogami: „Ida Cupas: Mega inspiracje! Super Zapraszam do siebie, nowy post http://idacupas.blogspot.com/ <3”. Powiązania z innymi blogerami stanowią

40 Tamże, 34. 
strategię uzasadniającą istnienie bloga i pokazującą ich wartość, tak dla użytkowników, jak i środowiska modowego. Jest to rodzaj publicznego uznania kompetencji i autorytetu blogerek wpisany w proces instytucjonalizowania ich roli.

Dystans między blogerkami a czytelnikami spoza branży staje się coraz bardziej widoczny. Zgodnie z sugestiami McQuarrie’a, Millera i Phillipsa śledzenie bloga przez konsumentów-czytelników szukających wskazówek i inspiracji stawia ich raczej w roli publiczności niż członków tej blogowej społeczności ${ }^{41}$. Ewentualnie stają się fanami, podczas gdy blogerki zyskują status ekspertek i celebrytek.

\section{Podsumowanie}

Początkowo blogi modowe były domeną kreatywnych, ekspresyjnych młodych dziewczyn, które fotografowały własne stylizacje. Były amatorkami, fankami mody, dowodzącymi (też sobie), że posiadają kompetencje, by dzielić się swoim hobby w mediach społecznościowych. Kooptacja blogerek do przemysłu modowego i komercjalizowanie ich medialnych kanałów pociągnęły za sobą odchodzenie od modelu relacyjnego, to jest od dzielenia się doświadczeniami i ich wymianą na rzecz popularyzacji dominującego dyskursu mody i demonstrowania łączącego się z nią prestiżu. Blogi, zwłaszcza blog Kuczyńskiej, zaczęły pełnić jedynie logistyczną funkcję dostarczyciela promocyjnych informacji i pośredniczenia w ich obiegu. Tamara Perea jeszcze aranżuje produkty z własnymi dodatkami, pozuje w odpowiednich stylizacjach, jej zespół robi między innymi profesjonalne zdjęcia, wplatając je we własny dyskurs autentyczności, ale ma on charakter monologowy, jednokierunkowy. Można, co oczywiste, wskazywać na istotną rolę blogerek w selekcjonowaniu informacji modowych, nie zmienia to jednak faktu, że ich strony są kanałem transmisji obowiązujących prawideł mody, a nie pomostem między nimi autorkami a czytelnikami.

Istotny w procesach komercjalizacji tych początkowo oddolnych dyskursów okazuje się już nie tyle opór ich autorów przed kooptacją do systemu, na co wskazywali brytyjscy przedstawiciele studiów kulturowych, ale świadome urynkawianie i autokomodyfikacja (którą Perea próbuje łączyć z własnym poczuciem modowej estetyki). To inna generacja bricoleurs niż przedstawiciele badanych w latach osiemdziesiątych i dziewięćdziesiątych subkultur. Dylematy tamtych osób publicznych dotyczyły tego, czy powinni brać udział w promowaniu towarów, dziś natomiast rozważają (jeśli w ogóle), czy reklamowany towar będzie pasował do ich wizerunku.

41 Albert M. Muñiz, Thomas C. O’Guinn, „Brand Community”, Journal of Consumer Research 27 (2001), 4. 
Czerpanie zysków z treści publikowanych w mediach nie jest niczym nagannym, ale dlaczego nie idzie w parze z rzetelnym informowaniem, dyskusją, dzieleniem się doświadczeniami, wiedzą, zwłaszcza że taka dialogowa konwersacyjność - ale i wiarygodność - mogą zwiększać marketingową skuteczność? Zamiast tego najpopularniejsze polskie blogerki oferują platformy - by użyć pojęcia Rona Eisenberga - „infotainmentu” ${ }^{42}$. Nie mają one nic wspólnego z Bachtinowskim dialogiem, czy „publiczną sferą”, o której wciąż przypominają kontynuatorzy myśli Jürgena Habermasa ${ }^{43}$, z rodzajem dyskursywnej „trzeciej przestrzeni”, w której wszyscy uczestnicy mogą wyrażać swoje zdanie, co pozwalałoby na rozwój przemysłu modowego. Być może takie demokratyczne współuczestnictwo nie jest możliwe w świecie mody? Czy egalitarystycznej koncepcji, opartej na zasadzie równych szans, nie da się pogodzić z elitarnością bazującą na zasadzie kompetencji czy niedostępności? Wielu może pukać do tych drzwi, ale zapraszani będą tylko nieliczni?

Analizowane tu najpopularniejsze polskie blogi modowe nie stanowią żadnego wyzwania dla dominujących w przemyśle mody prawideł. Wręcz przeciwnie, wszystkie kulturowe paradoksy współczesnego kapitalizmu pozostają nienaruszone: piękna i komercji, pragnień i dyscypliny, samoekspresji i autopromocji, Simmelowskiego bycia wyjątkowym i jednocześnie podobnym do innych. Jeśli zakładamy, że Web 2.0 korzysta z konwersacji jako głównego trybu ekspresyjnego, że media społecznościowe będą wspierać partycypacyjne, dialogowe modele, to ten model komunikowania, jak się okazało, ma niewiele wspólnego z analizowanym tu dyskursem.

\section{Bibliografia}

Bachtin, Michaił. „Problem tekstu: próba analizy filozoficznej”. Tłum. Jerzy Faryno. Pamiętnik Literacki 68 (1977), 3: 265-288.

Bachtin, Michaił. Twórczość Franciszka Rabelais'go a kultura ludowa średniowiecza i renesansu. Tłum. Anna i Andrzej Goreniowie. Kraków: Wydawnictwo Naukowe PWN, 1975.

Berry, Jess. „Street-Style: Fashion Photography, Weblogs and the Urban Image”. W: Fashion Capital. Style Economies, Sites and Cultures, red. Jess Berry, 129-148. Oxford: Interdisciplinary, 2012. Bohuszewicz, Paweł. „Dialog i monolog: o względności genologicznych przeciwstawień”. Litteraria Copernicana 15 (2015), 1: 28-39.

Boutang, Yann Moulier. Cognitive Capitalism. Cambridge: Polity Press, 2011.

\footnotetext{
42 Michael D. Murray, Encyclopedia of Television News (Westport, Greenwood Publishing Group, 1998), 103-105.

43 Jürgen Habermas, Strukturalne przeobrażenia sfery publicznej, tłum. Wanda Lipnik, Młgorzata Łukasiewicz (Warszawa: Wydawnictwo Naukowe PWN, 2007).
} 
Bowman, Shayne, Chris Willis. We Media: How audiences are shaping the future of news and information. The Media Center, 2003. Dostęp 21.04.2019. http://www.hypergene.net/wemedia/ download/we_media.pdf.

van Dijk, Teun A. Dyskurs jako struktura i proces. Tłum. Grzegorz Grochowski. Warszawa: Wydawnictwo Naukowe PWN, 2001.

Doupnik, Elizabeth. Julia Kuczyńska Tops List of 20 Most Revenue-Generating Social Personalities. „WWD”, 23.01.2017. Dostęp 18.02.2019. http://wwd.com/business-news/ media/20-most-influential-bloggers-10759942.

Duda, Aneta. Medialne socjotechniki brandcastingu. Hybrydyzacja. Uwiarygodnianie. Zadaniowość. Lublin: Katolicki Uniwersytet Lubelski, 2018.

Duszak, Anna, Norman Fairclough. Krytyczna analiza dyskursu. Interdyscyplinarne podejście do komunikacji społecznej. Kraków: Universitas, 2008.

Fairclough, Norman. „Language in New Capitalism”. Discourse \& Society 13 (2002): 163-166.

Friedman, Thomas L. „Need a Job? Invent It”. The New York Times, 30.03.2013. Dostęp 12.04.2019. https://www.nytimes.com/2013/03/31/opinion/sunday/friedman-need-a-job-invent-it.html.

Fuchs, Christian. Digital Labour and Karl Marx. London-New York: Routledge, 2014.

Jenkins, Henry, Sam Ford, Joshua Green. Spreadable Media, Creating Value and Meaning in a Networked Culture. New York: University Press, 2013.

Habermas, Jürgen. Strukturalne przeobrażenia sfery publicznej. Tłum. Wanda Lipnik, Małgorzata Łukasiewicz. Warszawa: Wydawnictwo Naukowe PWN, 2007.

Khamis Susie, Alex Mun. „The Three Cs of Fashion Media Today: Convergence, Creativity \& Control”, Journal of Media Arts Culture 7 (2010).

Krzysztofek, Kazimierz. „WEBski świat: mądrość tłumów sieciowych czy zbiorowe nieuctwo? Wprowadzenie”. W: Andrew Keen, Kult amatora. Jak Internet niszczy kulturę. Tłum. Małgorzata Bernatowicz, Katarzyna Topolska-Ghariani, 11-23. Warszawa: Wydawnictwa Akademickie i Profesjonalne, 2007.

Krzysztofek, Kazimierz. „Zmiana permanentna? Refleksje o zmianie społecznej w epoce technologii cyfrowych”. Studia Socjologiczne 4 (2012): 7-39.

Kubik, Anna. „Najlepsze blogi modowe”. Influencer.pl, 28.06.2016. Dostęp 18.02.2019. http://www. influencer.pl/237/najlepsze-blogi-modowe-zobacz-ich-wlascicielki.

Lévi-Strauss, Claude. Myśl nieoswojona. Tłum. Andrzej Zajączkowski. Warszawa: Wydawnictwo Naukowe PWN, 1969.

Marwick, Alice E. Status Update. Celebrity, Publicity, and Branding in the Social Media Age. New Haven: Yale University Press, 2013.

McQuarrie, Edward, Jessica Miller, Barbara Phillips. „The Megaphone Effect. Taste and Audience in Fashion”. Blogging Journal of Consumer Research 40 (2013), 1: 152. 
Mrozowski, Maciej. Media masowe władza, rozrywka i biznes. Warszawa: Oficyna Wydawnicza ASPRA-JR, 2012.

Muñiz, Albert M., Thomas C. O’Guinn. „Brand Community”. Journal of Consumer Research 27 (2001), 4: 412-432.

Murray, Michael D. Encyclopedia of Television News. Westport, Greenwood Publishing Group, 1998.

„Najpopularniejsze-polskie-blogi”. Newsbook, 17.06.2016. Dostęp 18.02.2019. https://newsbook. pl/2016/06/17/najpopularniejsze-polskie.

Nardi, Bonnie A., Diane Schiano, Michelle Gumbrecht, Luke Swartz. „«I'm Blogging This» A Closer Look at Why People Blog”. Communication of the ACM (2004). Dostęp 18.04.2019. https://www. academia.edu/32459914/Im_blogging_this_A_closer_look_at_why_people_blog.

Neff, Gina. Venture labor: Work and the burden of risk in innovation industries. Cambridge: MIT Press, 2012.

„Poznaj polskich blogerów”. BLOGmedia (2016). Dostęp 14.04.2019. http://www.blog-media.pl/ raport.

„Ranking i badanie polskiej blogosfery 2016”. Mediarun, 26.10.2016. Dostęp 20.02.2019. http:// mediarun.com/pl/digital/internet/blogerzy-wiedza-jak-zachecic-czytelnikow.html.

Rosen, Jay. The Weblog. An Extremely Democratic Form in Journalism. Dostęp 11.04.2018. http:// extremedemocracy.com/chapters/Rosen_weblog.pdf.

Ross, Andrew. Nice Work if you Can Get it. New York: NYU Press, 2009.

Sikora, Teresa Joanna. „Komodyfikacja cielesności w erze późno nowoczesnej”. W: Ciało w dobie współczesności. Wybrane zagadnienia z problematyki obrazu własnego ciała, red. A. Brytek-Matera, 239-260. Warszawa: Difin, 2010.

Storey, John. Studia kulturowe i badania kultury popularnej. Teorie i metody. Tłum. Janusz Barański. Kraków: Wydawnictwo Uniwersytetu Jagiellońskiego, 2003.

Technorati Media „Digital Influence Report” (2013), 4-13. Dostęp 13.04.2019. http://technorati. com/wp-content/uploads/2013/06/tm2013DIR1.pdf. 


\section{The discourse of fashion blogs: Between cooperation and co-optation}

\section{Summary}

Blogs are often the subject of enthusiastic interpretations due to their democratizing, dialogizing and grassroots potential. This article aims to discover if blogs provide for consumer participation and criticism. As a starting point, this study applies Bakhtin's framework of dialog to the field of fashion through the mixed methods of critical discourse analysis and content analysis. I show how the features of blogs provide methods for the "monologization" of their discourse. The paper presents the results of my analysis of two of the most popular Polish fashion blogs. My approach focused on reconstructing their process of legitimization through time, showing that they were far from being authentic, autonomous and collaborative. The fashion blogs examined here were consciously commercialized over time, becoming increasingly hierarchical, one-way, market-driven and self-promotional, and thus fully immersed in the logic and the values of fashion industry.

\section{Keywords}

critical discourse analysis, fashion blog, dialogue, monologue 